\title{
Perancangan Perpustakaan Umum dengan Pendekatan Arsitektur Hybrid
}

\author{
Armeinda Nur Aini dan Arina Hayati \\ Departemen Arsitektur, Fakultas Teknik Sipil dan Perencanaan, Institut Teknologi Sepuluh Nopember (ITS) \\ e-mail: arina_h@arch.its.ac.id
}

\begin{abstract}
Abstrak-Kota Surabaya telah ditetapkan sebagai Kota Literasi pada tahun 2014 diiringi dengan bertambahnya fasilitas taman bacaan dan beberapa perpustakaan untuk meningkatkan minat baca. Sebagai Kota Literasi seharusnya masyarakat umum berpartisipasi, namun karena kurangnya informasi, masyarakat belum sepenuhnya memanfaatkan dan menggunakan fasilitasfasilitas literasi yang ada. Faktor lain yang mempengaruhi menurunnya jumlah pengunjung ke fasilitas literasi adalah kurangnya minat baca masyarakat dan bangunan yang ada kurang memiliki desain yang menarik dan fasilitas yang kurang memadai. Berdasarkan isu diatas, maka tujuan dari perancangan ini untuk menjawab bagaimana suatu desain arsitektur hadir sebagai pemicu kegiatan literasi yang lebih menarik dan mudah untuk diakses oleh masyarakat umum. Rancangan bangunan perpustakaan diajukan sebagai tempat kegiatan literasi, edukatif dan rekreatif. Perancangan ini menggunakan pendekatan dan metode perancangan arsitektur hybrid yang menggabungkan dua fungsi yaitu perpustakaan dan taman sehingga dapat memberikan persepsi yang berbeda. Hasil rancangan perpustakaan mefokuskan pada menyelesaikan tiga kriteria desain yaitu bangunan yang dapat meningkatkan minat baca, sebagai wadah kegiatan edukasi serta bangunan dapat menjadi identitas literasi pada daerah tersebut.
\end{abstract}

Kata Kunci-Arsitektur Hybrid, Literasi, Minat baca, Perpustakaan, Taman.

\section{PENDAHULUAN}

L ITERASI sebagai kemampuan untuk mengidentifikasi, memahami, menafsirkan, membuat, berkomunikasi dan menghitung, menggunakan media cetak dan ditulis dengan konteks yang berbeda-beda. Literasi memungkinkan individu untuk mencapai suatu tujuan, mengembangkan pengetahuan dan potensi. Pemerintah kota Surabaya mencanangkan Kota Surabaya sebagai "Kota Literasi" bersamaan dengan peringatan hari Pendidikan Nasional pada 2014 dan menjadikan Kota Surabaya sebagai kota yang memiliki budaya membaca [1]. Untuk mendukung Kota Literasi, sudah diterapkan kegiatan tersebut di sekolah formal dengan menyediakan 5 menit bagi siswa untuk membaca dan tersedianya fasilitas seperti taman baca dan pojok baca di sudut tempat umum tertentu serta perpustakaan sekolah.

Untuk mewujudkan Kota Literasi tidak hanya dari segi formal tetapi dapat dengan segi informal seperti adanya taman baca di beberapa lingkungan warga serta perpustakaan kota. Walaupun label Kota Literasi telah dicanangkan, masyarakat

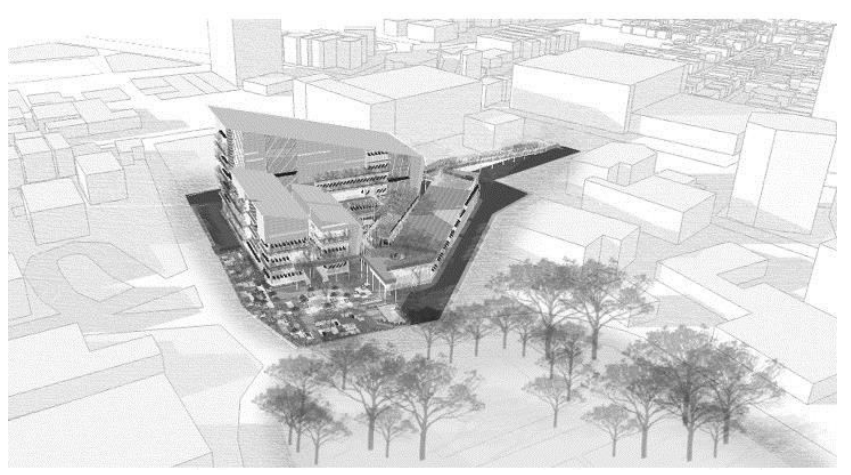

Gambar 1. Perspektif.

(Sumber: Dokumentasi Pribadi)

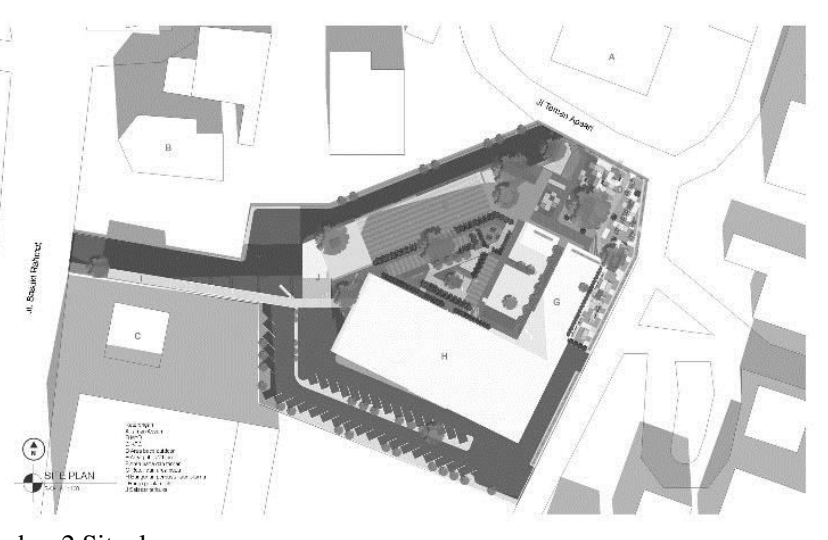

Gambar 2 Siteplan

(Sumber: Dokumentasi Pribadi)

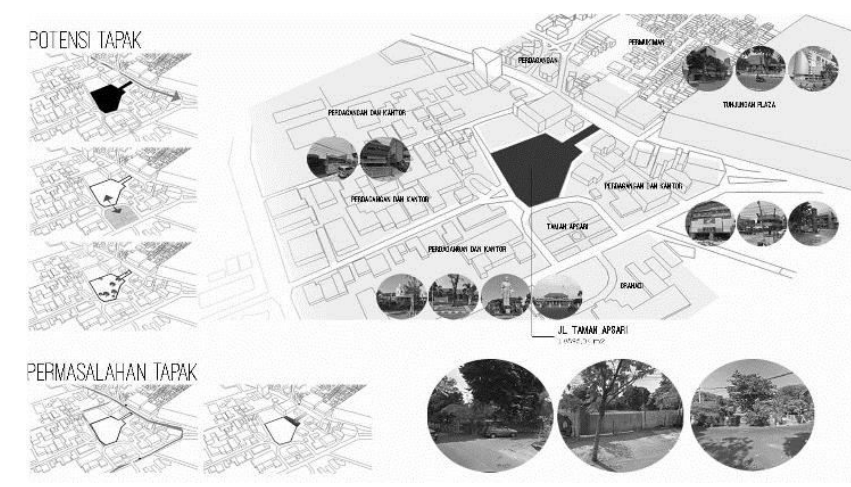

Gambar 3 Analisa Tapak

(Sumber: Dokumentasi Pribadi) 
Surabaya masih belum memiliki minat baca yang cukup besar karena beberapa faktor. Faktor-faktor tersebut antara lain kurang lengkapnya koleksi dan pemutakhiran referensi buku/bacaan, kurangnya penggunaan tekonologi multimedia dan keengganan masyarakat untuk mengunjungi perpustakaan/taman baca [2]. Disamping itu kondisi perpustakaan yang terkesan kaku menjadikan persepsi bahwa perpustakaan adalah tempat yang membosankan dan banyaknya lokasi yang kurang strategis menjadikan bangunan kurang dapat dijangkau oleh masyarakat.

Dengan adanya isu tersebut maka objek rancang berupa perpustakaan umum diajukan untuk dapat memberikan solusi permasalahan berkaitan dengan kegiatan literasi dan pusat informasi (Gambar 1 dan 2). Sebuah perpustakaan umum memiliki fungsi untuk memenuhi permintaan bagi generasi masa depan, termasuk perpustakaan dapat bermanfaat langsung bagi masyarakat yang hidup, bekerja atau belajar pada daerah tersebut. Perpustakaan umum juga diharapkan dapat menjadi tempat akses belajar teknologi maju, namun juga dapat menjadi tempat berkumpul yang rekratif, menarik dan menyenangkan [3].

\section{METODE PERANCANGAN}

Lokasi desain ditentukan berdasarkan isu sebelumnya dengan memilih lokasi yang lebih strategis dan memiliki potensi. Lahan terletak di pusat kota dengan tingkat keramaian yang tinggi yaitu di Jl. Taman Apsari, yang berseberangan dengan Taman Apsari, lingkungan perkantoran, area komersil, sekolah dan bangunan cagar budaya daerah Tunjungan. Dengan letak berada di pusat kota maka akan mudah dijangkau dan menarik minat masyarakat (Gambar 3).

Perpustakaan yang dikenal sebagai tempat yang kaku, formal dan membosankan perlu dilakukan perubahan persepsi di mana perpustakaan tidak hanya sebagai wadah untuk kegiatan membaca tetapi juga dapat menjadi wadah untuk aktifitas lainnya termasuk berkumpul, rekreasi, bersantai, dan lain sebagainya. Untuk itu, perancangan ini menggunakan pendekatan Arsitektur Hybrid dengan menggabungan dua fungsi yang berbeda untuk meningkatkan kualitas bangunan perpustakaan.

Adapun tahapan-tahapan dalam pendekatan Arsitektur Hybrid [4]:

1. Elektik atau quatation

Menelusuri dan memilih pembendaharaan bentuk dan elemen arsitektur dari masa lalu yang dianggap potensial untuk diangkat kembali atau telah mapannya makna yang diterima dan dipahamai masyarakat.

2. Manipulasi atau modifikasi

Elemen eketik selanjutnya dimanipulasi atau dimodifikasi dengan cara menggeser, mengubah dan atau memutar balikkan makna yang telah ada.

3. Penggabungan

Penggabungan dan penyatuan beberapa elemen yang telah dimanipulasi atau dimodifikasi ke dalam desain.

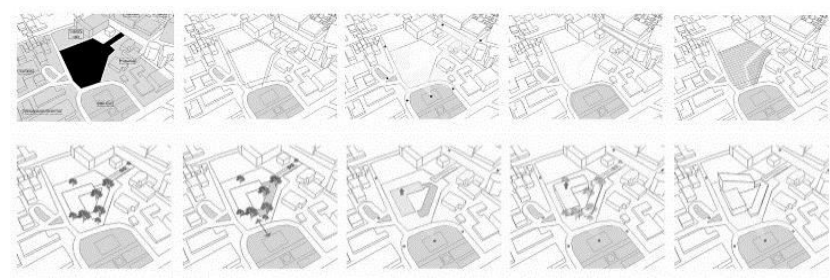

Gambar 4 Diagram Bentuk Bangunan

(Sumber: Dokumentasi Pribadi)
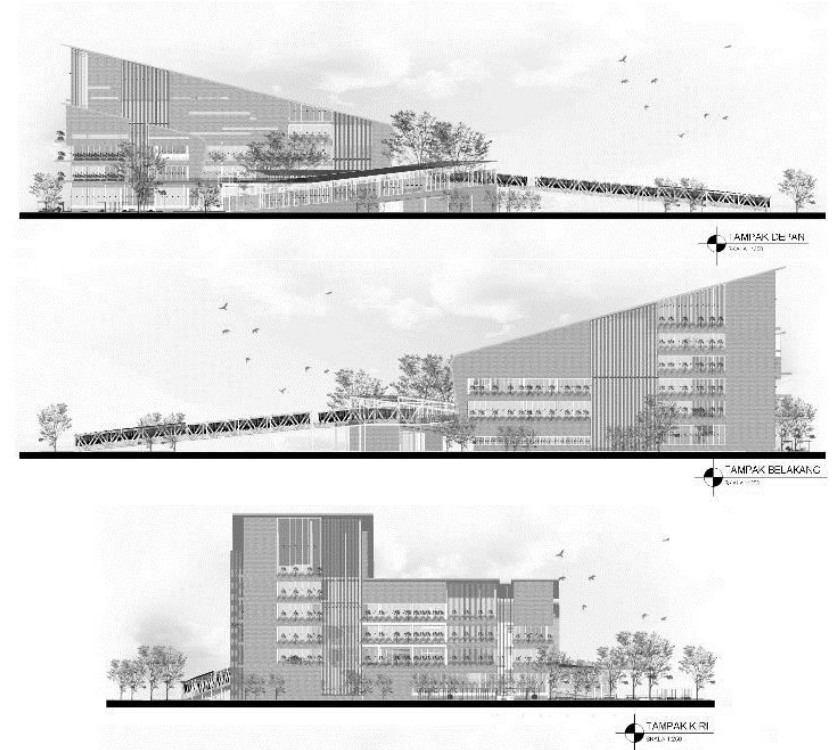

Gambar 5 Tampak Bangunan

(Sumber: Dokumentasi Pribadi)

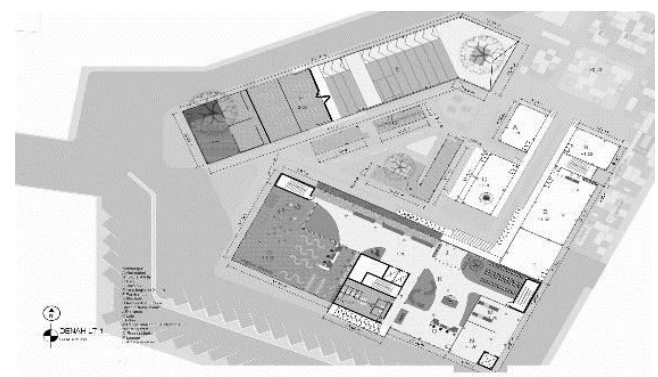

Gambar 6 Denah Lantai 1

(Sumber: Dokumentasi Pribadi)

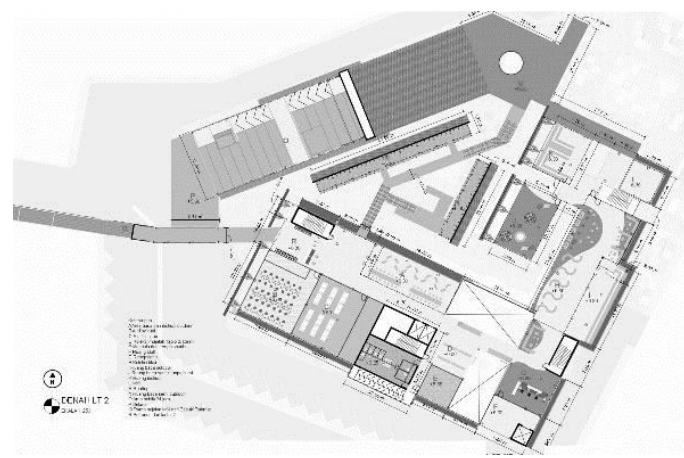

Gambar 7 Denah Lantai 2

(Sumber: Dokumentasi Pribadi) 


\section{HASIL DAN EKSPLORASI}

Untuk dapat memenuhi kebutuhkan masyarakat sehingga memicu kepekaan kegiatan literasi dibutuhkan kriteria desain yang mendukung konsep desain dengan menerapkan metode desain pada arsitektur hybrid, sebagai berikut:

Kriteria Desain 1: Objek dapat memberikan persepsi yang berbeda untuk meningkatkan literasi.

Konsep: menggabungkan dua fungsi berbeda.

Dengan menggabungkan dua fungsi yang berbeda, yaitu perpustakaan dan taman (karena sesuai dengan konteks lokasi yang berada di tengah kota dan berdekatan dengan Taman Apsari), perancangan bertujuan untuk menarik minat pengunjung pada objek dengan potensi lokasi ramai dan sering dikunjungi masayarakat sekitar.

Tabel 1

Konsep Hybrid

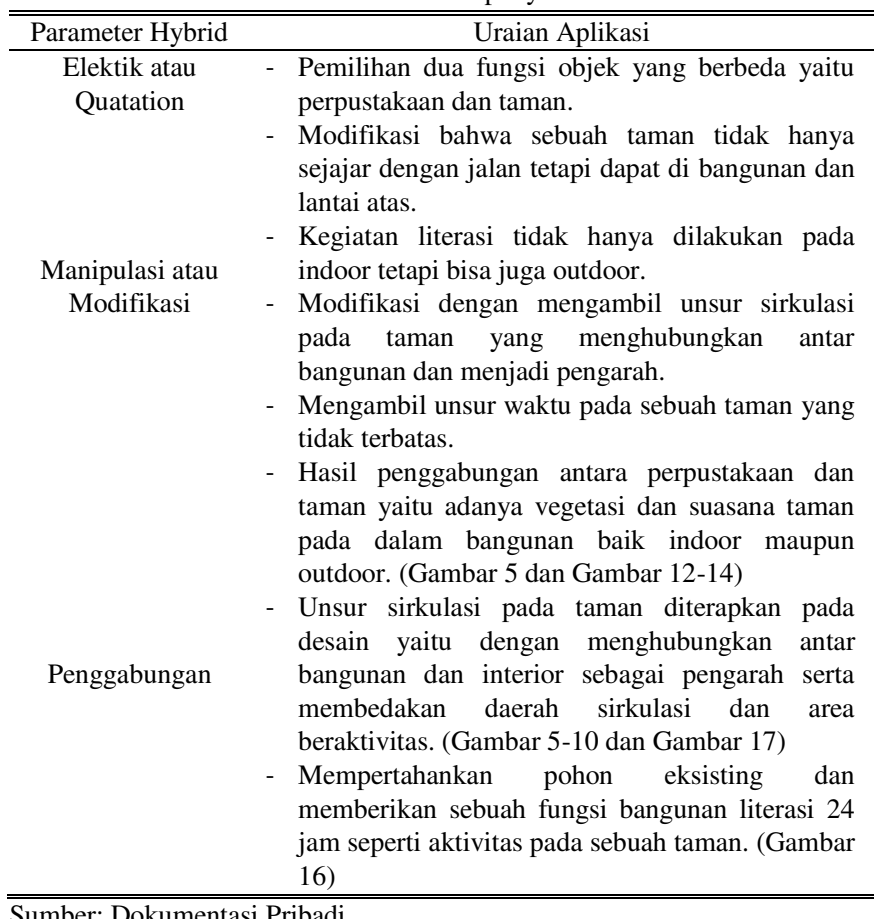

Kriteria desain 2: Objek mampu memenuhi kebutuhan literasi dengan suasana edukatif dan rekreatif.

Konsep edukatif:

- Memberikan fasilitas penunjang seperti mini bioskop dan ruang audiovisual untuk mengakses secara online. (Gambar 6)

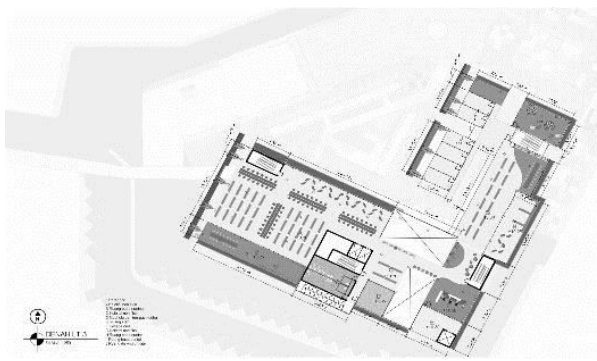

Gambar 8 Denah Lantai 3

(Sumber: Dokumentasi Pribadi)

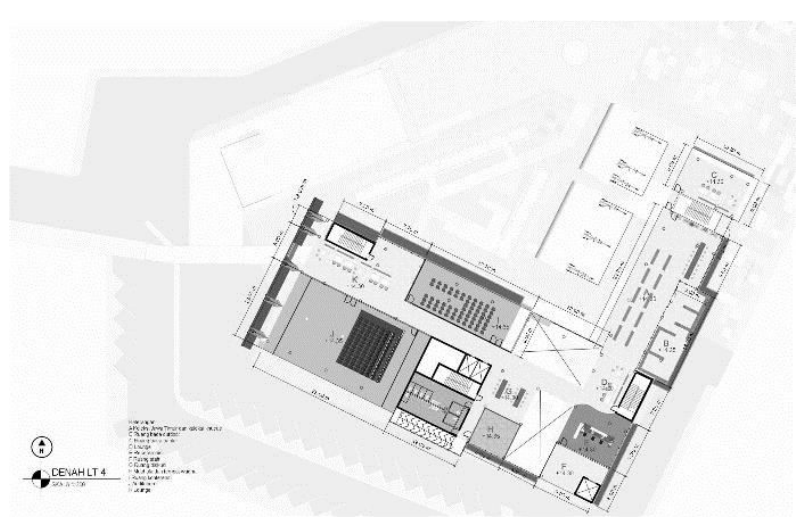

Gambar 9 Denah Lantai 4

(Sumber: Dokumentasi Pribadi)

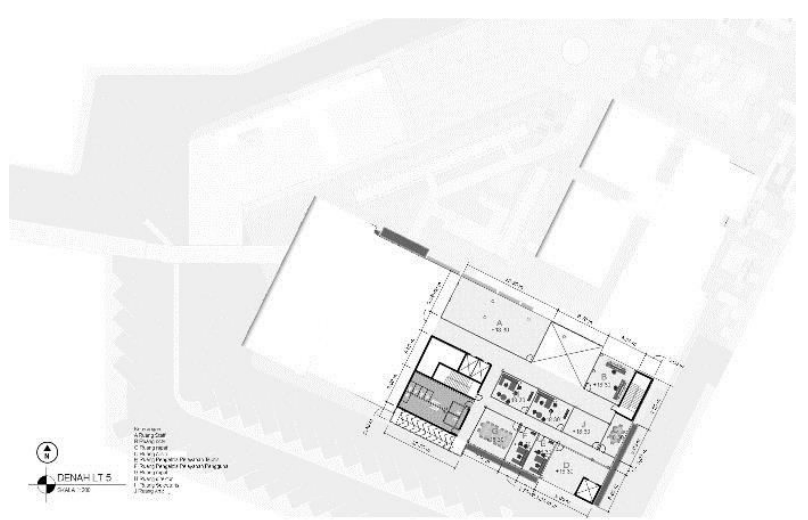

Gambar 10 Denah Lantai 5

(Sumber: Dokumentasi Pribadi)

- Pembagian zona fungsi pada taman bagian luar sehingga aktivitas antara kegiatan literasi yang membutuhkan ketenangan dan keramaian berbeda. (Gambar 11)

- Memberikan fasilitas digital tiap lantai. (Gambar 5-9)

Konsep rekreatif:

- Adanya fasilitas penunjang seperti retail berupa toko alat tulis, toko buku dan kafe. (Gambar 5)

- Pembagian zona pada bangunan kegiatan literasi dengan fasilitas lain.

Tabel 2.

\begin{tabular}{ll}
\hline \multicolumn{2}{c}{ Zona Membaca } \\
\hline \hline Zona & Aktifitas \\
\hline Tenang
\end{tabular}

Kriteria desain 3: Bangunan mampu memberikan identitas literasi pada daerah tersebut. 
Konsep: merepresentasikan bangunan literasi berdasarkan lingkungan sekitar.

- Memberikan sekuen pada lahan sehingga yang terlihat dari bagian depan yaitu berupa taman - taman + bangunan bangunan. (Gambar 1)

- Bentuk bangunan dan analisa tapak melihat dari keadaan lingkungan sekitar. (Gambar 4)

- Konsep material berupa batu alam secara umum karena mengambil dari material yang berada di taman, berwarna abu-abu mengikuti warna bangunan sekitar yang monokrom dan bukaan besar yang menyerupai bangunan Grahadi dan bangunan lama sekitarnya. (Gambar 4-5)

- Konsep sirkulasi pada bangunan memiliki beberapa pintu masuk karena merupakan fasilitas umum. Tetap membedakan antara pintu masuk kendaraan dan pejalan kaki. Terdapat pintu masuk pejalan kaki yang berasal dari Jl. Basuki Rahmat yang menghubungkan langsung ke lantai dua perpustakaan. (Gambar 2 dan Gambar 15)

\section{KESIMPULAN}

Literasi berhubungan dengan sumber informasi baik cetak maupun media. Isu mengenai rendahnya minat baca dan fasilitas baca menjadikan taman baca dan perpustakaan rendah akan pengunjung. Dengan demikian, objek rancang berupa perpustakaan umum diajukan untuk mewadahi kegiatan literasi dengan pendekatan hybrid. Metode rancang yang digunakan adalah metode arsitektur hybrid dengan menggabungkan kedua fungsi yang berbeda, yaitu perpustakaan dan taman. Fungsi taman dipilih karena melihat potensi lingkungan sekitar termasuk adanya Taman Apsari yang menarik serta rekreatif bagi masyarakat sekitar. Merubah persepsi masyarakat terhadap bangunan perpustakaan yang membosankan menjadi hal yang menarik dengan memasukkan fungsi bangunan tidak hanya mewadahi aktivitas membaca di dalam bangunan tetapi juga aktivitas belajar dan membaca dapat dilakukan di luar bangunan dengan menikmati suasana taman di sekelilingnya. Tidak hanya fungsi dan suasana taman yang menjadi aktivitas di dalamnya, terdapat fungsi penunjang berupa retail, kafe, ruang bersama disediakan agar masyarakat dapat melakukan aktifitas lainnya bersamaan dan merubah persepsi tentang sebuah perpustakaan pada umumnya.

Dengan adanya objek rancang tersebut diharapkan dapat menjawab isu yang ada dengan tujuan agar masyarakat sadar akan pentingnya kegiatan literasi dan dapat meningkatkan minat baca sehingga Kota Surabaya layak disebut sebagai Kota Literasi.

\section{DAFTAR PUSTAKA}

[1] Antaranews, "Surabaya Deklarasikan Kota Literasi." [Online]. Available: http://www.antaranews.com/berita/432307/surabaya-deklarasikansebagai-kota-literasi.

[2] Antaranews, "Legislator Prihatin Minat Baca Masyarakat Surabaya Rendah.” [Online]. Available: http://jatim.antaranews.com/berita/196574/legislator-prihatin-minat-bacamasyarakat-surabaya.

[3] B. Edwards, "Libraries and Learning Resource Centres," United Kingdom, 2009.

[4] F. Rompis, Hibridisasi Fungsi Pasar Tradisional dan Mall, Suatu Studi Imajinatif. Manado, 2013. 